\title{
Eclampsia in N'Djamena Mother and Child University Hospital Center: Epidemiology and Prognosis
}

\author{
Foumsou Lhagadang ${ }^{1,3,}$, Gabkika Bray Madouée ${ }^{3}$, Kaboro Mignagnal ${ }^{1,2}$, Ibrahim Hamat ${ }^{1,2}$, \\ Doumbia Madjouma Badra A ${ }^{2}$, Sadjoli Damthéou ${ }^{1,3}$, Sendé Rock ${ }^{1}$ \\ ${ }^{l}$ Faculty of Human Health Sciences, N'Djamena, Chad \\ ${ }^{2}$ N'Djamena National General Reference University Hospital, Chad \\ ${ }^{3}$ N'Djamena Mother and Child University Hospital, Chad
}

\begin{abstract}
*Corresponding Author: Foumsou Lhagadang, Professor, Assistant in N'Djamena University, Department of Gynaecology and Obstetrics of the Human Health Sciences Faculty. Email : foumlhaga@ gmail.com
\end{abstract}

\begin{abstract}
Background: Eclampsia, a major complication of severe preeclampsia is a serious medical and obstetric emergency, threatening maternal and fetal lives.
\end{abstract}

Objetive: improve the management of eclampsia.

Patients and method: This was an analytic and prospective study, performed in the Maternity of N'Djamena Mother and Child University about the prognosis and epidemiological aspects of eclampsia, covering one year period from July $1^{\text {st }}$, 2016 till June $30^{\text {th }}$, 2017. All pregnant woman or parturient admitted in the service for a convulsive crisis or a loss of conciousness associated with a blood pressure $\geq 140 / 90 \mathrm{mmHg}$, a significant proteinuria ( $\geq 300 \mathrm{mg} / 24$ hours), with gestational term $\geq 20$ weeks of amenorrhea were recorded after getting consent

Results: We recorded 154 patients admitted for eclampsia among 8,282 deliveries giving a prevalence of 1.8 $\%$. The average age was 21.3 years with extremes going of 13 and 43 years. The caesarian section was realized in $67.5 \%$ cases. Complications were noted in 72 cases (46.7\%) mainly represented the renal failure in $24.6 \%$ for the mothers and fetal hypotrophy -(16.2\%) for baby. We registered 13 deaths giving a maternal lethality of $8.4 \%$. The perinatal mortality was $16.2 \%$.

Conclusion: Eclampsia is a disease that provides complications among mother and child. The management is linked with the implementation of protocol that can reduce the occurrence of these complications. The prevention must lead to adequate prenatal cares.

Keywords: eclampsia complications, epidemiological, prognosis, N'Djamena, Chad.

\section{INTRODUCTION}

Eclampsia, a major complication of severe preeclampsia is a serious medical and obstetric emergency, threatening maternal and fetal lives $[1,2]$. Its frequency is lower in industrialized countries [3] compared with developing countries where the frequency is high varying from 9.4 to $10.8 \%[4,5]$. It is a major cause of maternal and foetal morbidity, especially in developing countries [6].It is recognized to be the cause of 50,000 maternal deaths among the 500.000 maternal deaths recorded yearly in the world with a lethality rate of $10 \%$ [1]. In Chad it is responsible for $15 \%$ of the maternal deaths (860 maternal deaths for 100.000 live births) [7]. Objective: improve the management of the eclampsia to avoid the arisen of the complications.

\section{Patients And Method}

This was a prospective and analytical survey covering one year period from July $31^{\text {th }}, 2016$ to June $30^{\text {th }} 2017$ about eclampsia epidemiology and prognosis performed in N'Djamena mother and Child University Hospital.

All pregnant woman or parturient admitted in the service for a convulsive crisis or a loss of conciousness associated with a blood pressure $\geq 140 / 90 \mathrm{mmHg}$, a significant proteinuria 
( $\geq 300 \mathrm{mg} / 24$ hours), with gestational term $\geq$ 20 weeks of amenorrhea were recorded after getting consent. Those whose eclampsia occurred after delivery were not recorded

Studied variables were: age, educational level, profession, parity, mode of admission, number of prenatal care, period of arisen convulsive crisis, blood pressure, proteinuria, and mode of delivery, type of complication, management, maternal and fetal prognosis.

Data were analyzed using SPSS18.0. Chisquare $\left(X^{2}\right)$ test $(p<0.05)$ were used to compare variables.

\section{RESUlts}

\subsection{Frequency}

We have recorded 154 pregnant patients admitted for eclampsia among 8,282 deliveries, giving a frequency of $1.8 \%$.

\subsubsection{Complications}

Seventy two patients among the 154 patients recorded had presented complication giving a rate of $46.7 \%$. Main maternal complications were: acute kidney failure (24.6\%) and Abruption placental (7.1\%).

For fetal, mains complications were: fetal hypotrophy (16.2\%) and fetal asphyxia (7.1\%).

Table 1. Type of complications

\begin{tabular}{|l|c|c|}
\hline \multicolumn{1}{|c|}{ Complication } & n = 154 & \% \\
\hline Maternal & 38 & 24.6 \\
$\begin{array}{l}\text { Complication } \\
\text { Acute kidney failure } \\
\text { Abruptio placental }\end{array}$ & 11 & 7.1 \\
\hline HELLP syndrom & 9 & 5.9 \\
\hline disseminated & 7 & 4.5 \\
intravascular & & \\
coagulation & & \\
\hline Acute pulmonary & 3 & 2 \\
oedema & & \\
\hline Cerebro vascular & 4 & 2.6 \\
accident & 72 & 46.7 \\
\hline Total complications & & \\
Fetal compotrophy & 25 & 16.2 \\
Fetal hypotroph \\
fetal Asphyxia & 11 & 7.1 \\
Prematurity & 8 & 5.2 \\
Small for term & 8 & 5.2 \\
Total & 52 & 33.7 \\
\hline
\end{tabular}

Table II. link between complications and socio-demographic characteristics

\begin{tabular}{|c|c|c|c|c|c|c|}
\hline \multirow{3}{*}{$\begin{array}{c}\text { Socio-demographic } \\
\text { characteristics }\end{array}$} & \multicolumn{4}{|c|}{ Complications } & \multicolumn{2}{|c|}{ Khi' $^{2}$} \\
\hline & \multicolumn{2}{|c|}{ Yes } & \multicolumn{2}{|c|}{ No } & & \\
\hline & $\mathbf{n}$ & $\%$ & $\mathbf{n}$ & $\%$ & & \\
\hline $\begin{array}{l}\text { Age } \\
\leq 19 \text { ans }\end{array}$ & 46 & 59.8 & 31 & 40.2 & 10.43 & 0.001 \\
\hline$\geq 20$ ans & 26 & 33.8 & 51 & 66.2 & & \\
\hline Parity & 48 & 51 & 46 & 49 & 9.34 & 0.002 \\
\hline Primpara & 24 & 40 & 36 & 60 & & \\
\hline Parity $\geq 2$ & & & & & & \\
\hline Pregnancy follow up & & & & & & \\
\hline Attended prenatal cares & 14 & 21.8 & 50 & 78.2 & & \\
\hline No Attended prenatal cares & 58 & 64.4 & 32 & 35.6 & 27.23 & 0.000 \\
\hline Schooling & & & & & & \\
\hline Unschooled & 60 & 53.6 & 52 & 46.4 & & \\
\hline Schooled & 12 & 28.5 & 30 & 71.5 & 15.04 & 0.000 \\
\hline
\end{tabular}

Patients aged less than 20 years had developed more complications than those aged above 20 years. The difference was statistically significant $(\mathrm{p}=0.001)$.

Primiparous women had developed more complications than other parities .The difference was statistically significant $(p=0.002)$

Patients who had not attended prenatal consultations developed more complications. The difference was statistically significant $(\mathrm{p}=0.000)$
Unschooled patients had had more complications $(\mathrm{p}=0.000)$.

\subsubsection{Relation between number of convulsion and the occurrence of complications}

Patients that had had more than 3 convulsions presented complications (43 cases/72 giving $59.7 \%)(\mathrm{p}=0.001)$.

\subsubsection{Mode of delivery and maternal complications}

The majority (104 patients i.e. 67.6\%) had delivered by cesarean section, the 50 remaining had delivered by vaginal route (32.4\%). 
Forty seven (45.1\%) among patients delivered by cesarean had presented complications compared with 25 women who had given birth by cesarean section. Twenty five (50\%) in the group of patients delivered by vaginal had presented complications. The difference was not statistically significant between the mode of delivery and maternal complications $(\mathrm{p}=0.09)$.

\subsubsection{Management of maternal complications}

The commonest drugs used in management were: (Nicardipine, Clonidine) in $90 \%$ for the treatment of hypertension

Diazepam and the magnesium sulfate were used for the management of convulsion respectively in $13 \%$ and in $87 \%$

Eighteen patents had received a blood transfusion, of at least one bag. Blood product like plasma had been administrated in 13 patients.

Seventy patients $(11,1 \%)$ had undergone dialysis cure.

\subsubsection{Causes of maternal deaths}

Table III. Causes of maternal deaths

\begin{tabular}{|l|c|c|}
\hline \multicolumn{1}{|c|}{ Causes of maternal deaths } & n & \% \\
\hline Acute kidney failure & 5 & 3,2 \\
\hline $\begin{array}{l}\text { Disseminated intravascular } \\
\text { coagulation }\end{array}$ & 4 & 2,6 \\
\hline Hellp syndrome & 3 & 2 \\
\hline Acute pulmonary oedema & 1 & 0,6 \\
\hline Total & $\mathbf{1 3}$ & $\mathbf{8 , 4}$ \\
\hline
\end{tabular}

We had recorded thirteen maternal deaths, giving a maternal lethality of $8.4 \%$. The mains causes of maternal death were acute renal failure (3.2\%) disseminated intravascular coagulation $(2.6 \%)$.

\subsubsection{Fetal prognosis}

Twenty five fetal deaths were noted giving a perinatal mortality of $16.2 \%$. The analyze of fetal death had shown that 13 were delivered vaginal route ant the 12 remaining by cesarean section The difference was statistically significant $(p=0.022)$. Caesarean section seemed to be a factor of good fetal prognostic.

\section{DisCUSSION}

\subsection{Epidemiological Aspects}

\subsubsection{Frequency}

The frequency of eclampsia in this survey was $1.8 \%$. This rate is comparable to Abdoul-Aziz's [11] findings in 2013 in Dakar, Senegal, that reported a rate of $1.35 \%$. Therefore it is higher than those of Belley et al [12] in 2009 in Douala in Cameroon and Lankoande et al [9] in 1998 in Ouagadougou in Burkina Faso, which respectively $0.95 \%$ and $0.89 \%$.

\subsection{Maternal and Fetal Complications}

\subsubsection{Maternal complications}

Seventy two patients $(46.7 \%)$ had represented complications. Main maternal complications were represented by acute kidney failure (24.6\%) followed by abruption placental $(7.1 \%)$. Our findings confirm the literature data $[9,10$, 11, and 13] that reported renal failure as the first complication of eclampsia. This may be explained by the fact that eclampsia induced kidney lesions which cause an acute tubular nephropathies associated with glomerular endotheliosis lesions.

\subsection{Fetal Complications}

Hypotrophy (16.2\%) and birth asphyxia (7.1\%) were the most commonest noted fetal complications. Our results are comparable to those reported by Abdul Aziz [11] and Saleh [4] who found respectively $16 \%$ and $15.7 \%$ a rate of fetal hypotrophy due to eclampsia. This seems to be linked at e low proportion of patients that attended prenatal cares. Without screening during pregnancy surveillance, preeclampsia/eclampsia can lead to complication like small for term.

\subsection{Sociodemographic Characteristics and Complications}

Eclampsia is common in teenagers and young women. The majority of women that had presented complication were age less than 20 years $(n=46 / 72)$ with a statistically significant difference $(p=0.001)$. Ours result confirm previous findings that showing this age group as a group of risk factor for preeclampsia/ eclampsia and therefore likely to develop complications $[8,10]$

Unschooled patients had represented 76.6\%. According to Akpadza[13] in 1996 in Lomé, Togo, schooling is a major determinant of the onset of eclampsia. Unschooled patients do not know the virtues of prenatal consultation. They rarely attend prenatal cares because they do not know the danger signs advocated during this prenatal consultation.

Primiparous women were the most exposed group, representing $61.3 \%$ of the patients in this series $(p=0.002)$. Our result confirms previous Africans series that reported a proportion of 
primiparous varying from $59.6 \%$ to $66.6 \%$ among patients admitted for eclampsia $[6,7,9]$.

Lack of prenatal cares seems to be a factor allowing the occurrence of complication. This was confirmed in our series with 58 patients that haven't attended prenatal cares among this 72 that presented the complications $(\mathrm{p}=0.000)$. This situation is reported by many African authors in south of the Sahara [7, 13, 14]. For these authors, prenatal surveillance plays an important role in the occurrence of eclampsia. A high rate of prenatal cares is followed with a low incidency of eclampsia. This observation was made by Mayi-Tsonga[15] in 2006 in Libreville, Gabon and Mohamed[39] in 2013 in Nouakchott, Mauritania, who reported in their series a low prevalence of eclampsia among pregnant women that attended to prenatal cares.

\subsection{Clinical and Therapeutic Aspects}

\subsubsection{Relation between number of convulsion and the occurrence of complications}

Patients that had had more than 3 convulsions presented complications (43 cases/72 giving $59.7 \%)(\mathrm{p}=0.001)$. This could be explained by the delay for decision to look for care due to patient and their families.

\subsection{The mode of delivery}

The most common mode of delivery in this study was cesarean section (104 cases or $67.5 \%)$. Vaginal route was used in 50 cases $(32.5 \%)$. Several authors reported a proportion of cesarean section rates ranging from 48.8 to $97 \%$ for eclampsia $[2,4,7,13$, and 15]. This high rate of cesarean section could be explained by the severity of the pathology that can lead to maternal and fetal prognosis.

\subsection{Prognosis Aspects}

\subsubsection{Maternal prognosis}

We recorded 13 maternal deaths giving a lethality rate of $8.4 \%$. Maternal mortality due to eclampsia is very high in Africa [7]. Several African authors found higher rates than ours ranging from $10 \%$ to $21 \%[3,4,9,12]$. This high rate is due to the ignorance of this pathology by the population. Factors like lack of health facilities and good management of eclampsia in some African areas can explained these results.

\subsubsection{Fetal prognosis}

Perinatal mortality in this study was $16.2 \%$. This finding is like the reported data of African authors ranging from 14.6 to $27.9 \%$ [4, 5, 6, 12 , 13]. This rate can be explained by the delay to receiv adequate cares.

\section{CONCLUSION}

Eclampsia remains a major public health problem in Chad. Maternal and perinatal mortality related to complications of eclampsia in this study is high. The management is linked with the implementation of protocol that can reduce the occurrence of these complications. The prevention must lead to adequate prenatal cares.

\section{CONSENT}

For this survey we have obtained the agreement of the national Ethics Committee, Director of N'Djamena Mother and Child University hospital.

\section{REFERENCES}

[1] Launoy A, Sprunck O, Collange T, Pottecher. Pre-eclampsia, eclampsia, HELLP syndrome: definitions, diagnostic and management elements. 51 $1^{\text {st }}$ National Congress of Anesthesia and Resuscitation, Elsevier Masson SAS 2009:3-6.

[2] SimaZue B, Bernamar D, Ngaka C, Nguemby M. Anesthesia-Reanimation and Eclampsia in African settings: Experience of the Libreville hospital center. Med Afr Noire; 1998, 45(12): 2p6-

[3] Atade J, Adisso S. Eclampsia at the maternity ward of the Parakou Benin CHDU. Incidence and lethality. Geneva Foundation for Medical Training and Research, 2006:2-6.

[4] Saleh A, Foumsou L, AndjeffaV, Mignagnal K,Lokossou A, Perrin RX. Crises d'éclampsie à la Maternité de l'Hôpital Général de Référence Nationale de N'Djaména: aspects épidémiologiques, thérapeutiques et pronostiques. Journal de la Société de Biologie Clinique, 2014 ; $\mathrm{N}^{\circ} 020$; 64-68.

[5] Mayes M, Sweet B. Eclampsia: A serious complication of pregnancy. A Textbook for Midwives 12th Edition 1997:533-545.

[6] 6Ndaboine EM, Kihurwa A, Rumanyika R, Beatrice H, Massinde AN. Maternal and perinatal Outcomes among eclamptic patients admitted to Bugando Medical Centre, Mwanza, Tanzania. African Journal of Reproductive Health 2012;16(1):35-41.

[7] Cisse CT, Ewagnignin E, Hojeige A, Diadhiou $F$ Eclampsia in the African environment: Epidemiology and prognosis at DAKAR University Hospital. Week. Hospital. Paris 1997;73(33-34):1062-1067.

[8] Mellier G, MielletCh, Griot JP, Perrot D. Eclampsia: the analysis of a series of 18 
observations. Conduct to be followed in the event of a severe eclampsia crisis. Revue Française de gynécologie - obstétrique 1984, 79(4):271-275.

[9] Lankoande J, Toure B, Ouédraogo A. et al. Les éclampsies à la maternité du Centre Hospitalier National Yalgado Ouédraogo de Ouagadougou (Burkina Faso): Aspects épidémiologiques, cliniques et évolutifs. Med Afr Noire, 1998;45(6):1-4.

[10] Conferences of experts. Eclampsia. Clinical pharmacology of magnesium sulfate. In: Société Française d'Anesthésie et Réanimation (SFAR), Réanimation des formes de pré éclampsie, Paris, Elsevier 2000:107-128.

[11] Abdoul-Aziz D, Moussa D, Magate M, et al. Epidemiological profile and CEP of eclampsia in Senegal: 62 cases. Pan Afr Med J. 2013, 16:83-90.

[12] Belley PE, Nana Njamen T, Coulibaly A, Mboudou E, Doh A. Eclampsia at Douala
General Hospital: Epidemiological and prognostic aspects. Journal of Med Health Sci. 2009,10 (4):7-11.

[13] Akpadza K, Baeta S, Kotor KT, Hodonou AKS. Eclampsia at the Gynecology-Obstetrics Clinic at TOKOIN-LOME University Hospital (TOGO). Med Afr Noire 1996,43(3): 166-169.

[14] HariolyNirina MOJ, Rasolonjatovo TY, Andria Nirina M. Epidemiological profile of preeclampsia and eclampsia admitted to resuscitation of adults in the Befelatanana maternity ward. Journal of AnesthesiaResuscitation and Emergency Medicine, 2009;1(3):22-24.

[15] Mayi-Tsonga S, Akoua L, Ngou-Mve-Ngou JP, Meye JF. Risk factors for eclampsia in Libreville (Gabon): a case-control study. Cahiers santé 2006, 16(3):197-200.

[16] Konan BR, Olou NL, Adjoussou S. Delayed postpartum eclampsia in African settings. SAGO 2010;39p.

Citation: Foumsou Lhagadang, Gabkika Bray Madoué, Kaboro Mignagnal, Ibrahim Hamat, Doumbia Madjouma Badra A, Sadjoli Damthéou, Sendé Rock. Eclampsia in N'Djamena Mother and Child University Hospital Center: Epidemiology and Prognosis. 2020; 5(1):13-17. DOI:dx.doi.org/10.20431/2456-0561.0501 002 .

Copyright: (c) 2020 Authors. This is an open-access article distributed under the terms of the Creative Commons Attribution License, which permits unrestricted use, distribution, and reproduction in any medium, provided the original author and source are credited. 